\title{
Multifunctional Photonic Crystal Compact Demux-Detector on InP
}

\author{
F. Van Laere, D. Van Thourhout and R. Baets \\ Department of Information Technology (INTEC), Ghent University-IMEC, Sint-Pietersnieuwstraat 41, 9000, Gent, Belgium \\ frederik.vanlaere@intec.UGent.be \\ T. Stomeo and T.F. Krauss \\ School of Physics and Astronomy, Universtiy of St. Andrews, St. Andrews, Fife, KY16 9SS \\ M. Ayre, C. Cambournac and H. Benisty \\ Laboratoire Charles Fabry de l'Institut d'Optique, CNRS, Univ Paris-Sud, Campus Polytechnique, RD 128, F-91127 Palaiseau, France
}

\begin{abstract}
We demonstrate a very compact multifunctional photonic crystal device on InPmembrane. Grating-coupled fibers feed a multimode photonic crystal wedged waveguide accomplishing individually selectable coarse WDM demux within $20 \mu \mathrm{m}$ per channel toward membrane integrated detectors.

(C)2007 Optical Society of America

OCIS codes: (130.0130) Integrated Optics; (040.5160) Photodetectors; (050.2770) Gratings; (230.0230) Optical Devices
\end{abstract}

\section{Introduction}

High refractive index contrast is the route towards very dense integrated circuits. In the last few years, a lot of very compact devices have been demonstrated in high vertical index contrast Silicon-on-Insulator (SOI) [1]. However, active devices are still difficult in silicon. Recently, III-V material was heterogeneously integrated on Silicon, in which lasers and detectors were fabricated and coupled to the underlying silicon [2-3]. Also, very high performance detectors in epitaxially grown Germanium on Silicon were demonstrated [4].

In this paper, both active and passive functionalities are integrated in III-V material. The high vertical index contrast, needed for compact devices, is obtained by benzocyclobutene (BCB) wafer bonding [5]. Light is coupled vertically from the fiber to the device using small, i.e. fiber-core-sized, grating couplers. Polarization independent operation using polarization diversity is experimentally substantiated. As an application, we demonstrate a very compact photonic crystal demultiplexer in InP-membrane integrated with waveguide photodetectors, well suited for Metropolitan Area Networks.

\section{Device}

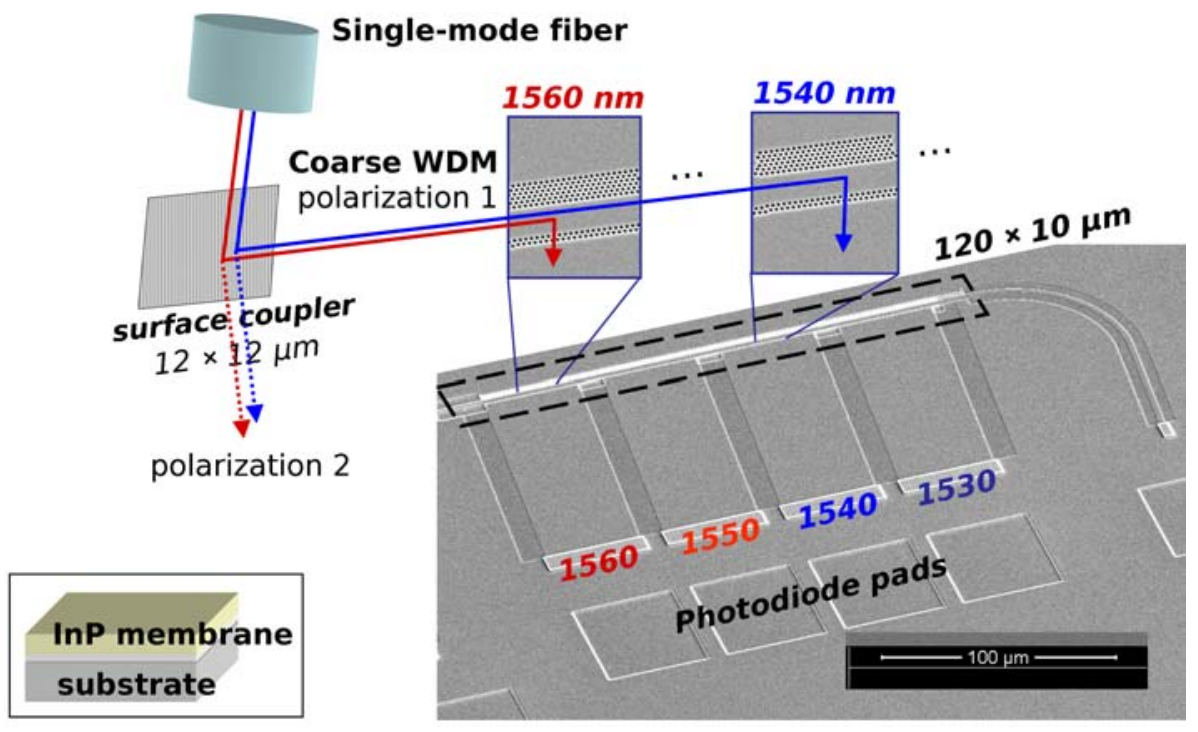

Fig. 1. Scheme of the compact demultiplexer technology embedded onto an InP-membrane. 
The global device layout is shown in Fig. 1. The basic layer stack is a $300 \mathrm{~nm}$-thick InP-membrane sandwiched between air and BCB (a low index polymer, $n=1.54$ at $1.55 \mu \mathrm{m}$ ) on a host-substrate. Compact $(12 \times 12 \mu \mathrm{m})$ surface grating couplers are used to inject light (near) vertically from single-mode fiber to waveguide [6]. Polarization diversity deals with the different fiber polarizations which are separated at the surface coupler [7]. The multiplex signals travel in a guide that becomes a highly specific multimode photonic crystal waveguide. This waveguide itself performs the spectrometer-demux action, as sketched here for two wavelengths, 1540 and $1560 \mathrm{~nm}$. The optical carriers then reach a set of decoupled photodiodes, suited to provide telecom-rate photocurrents. In the following paragraphs we will describe the different components of the device in more detail.

\section{Integrated p-i-n detectors on InP-membrane}

The layout of the p-i-n detector and the detector coupling principle are shown in Fig. 2. The light is first coupled from a single-mode fiber to an InP-membrane waveguide (slightly n-doped) by a compact grating coupler (Fig. 2 left) [6]. Coupling from InP-membrane waveguide to an underlying $500 \mathrm{~nm}$ InGaAs detector layer (Fig. 2 middle) is done evanescently. The first steps of the integration scheme involve detector mesa definition, followed by e-beam lithography of waveguides, photonic crystals ( $\mathrm{PhC}$ ), and gratings aligned to the mesas. After p-contact definition, the structure is bonded onto a host-substrate using BCB wafer bonding. After substrate and etch-stop layer removal, the $\mathrm{n}$-contact is defined and access to the p-contact (now at the bottom side) through a via is provided. A crosssection of a fabricated detector structure is shown in Fig. 2 (right).

The measured dark current of the detector $\left(12 \times 10 \mu \mathrm{m}\right.$ in this case) is $4 \mathrm{nA}$ at $V_{\mathrm{R}}=0.5 \mathrm{~V}$ reverse bias and the external responsivity (fiber to waveguide to detector) is $\eta=0.40 \mathrm{~A} / \mathrm{W}$. The grating coupler efficiency is estimated to be $30-40 \%$, which could be further increased by adding a bottom mirror to the grating [8].

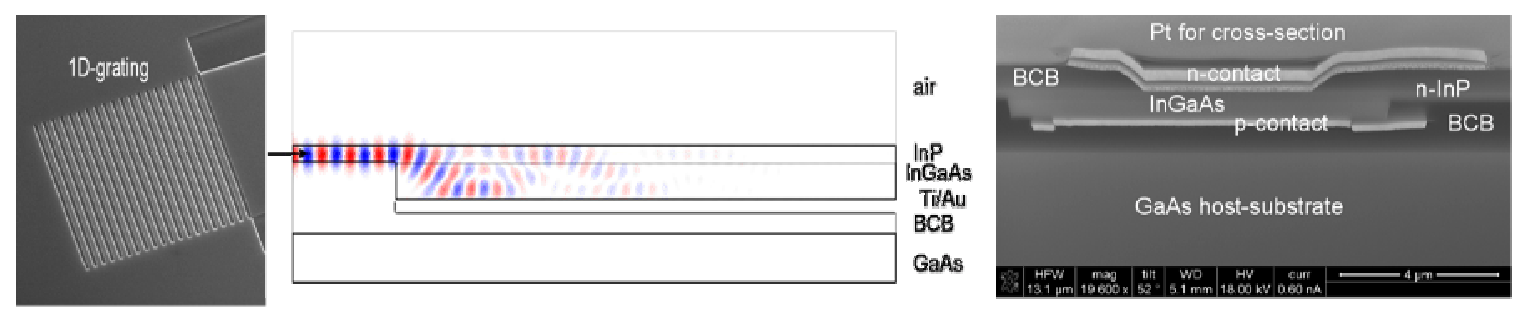

Fig. 2. (Left) Input grating coupler. (Middle) Simulation of the waveguide-to-detector coupling (only p-contact taken into account). (Right) Cross-section of a fabricated structure (p-contact access through via not shown here).

\section{Polarization diversity using grating couplers}

Gratings in a single waveguide configuration (previous section) are nearly perfectly polarizing. Thus, polarizationindependent operation can be obtained when using 2D gratings in a polarization diversity configuration [7]. We have implemented this approach, from fiber to detector. A 2D grating is put in the intersection of two near orthogonal waveguides. Both orthogonal polarization components from the light in the fiber couple to the TE mode of their own waveguide. At the output both arms are recombined in a detector (Fig. 3 left). For the measurement a fiber connected to a tunable laser is positioned over the input grating. The photocurrent is measured (reverse bias voltage of $0.5 \mathrm{~V}$ ) while changing the polarization of the input light randomly, using a polarization controller. This results in a polarization diversity loss (PDL) figure ( $\left.I_{\max } / I_{\min }\right)$ of only $0.35 \mathrm{~dB}$ (Fig. 3 right).
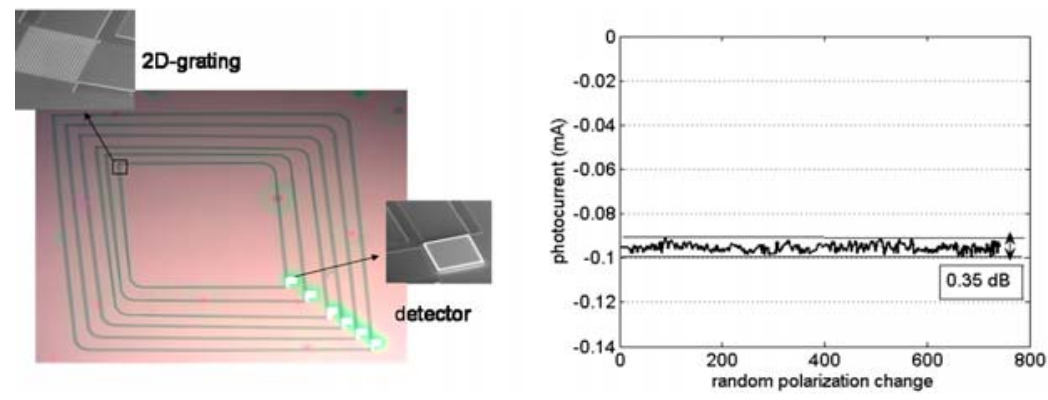

Fig. 3. Polarization diversity using 2D grating couplers. (Left) Sample layout prior to bonding. (Right) PDL measurement. 


\section{Photonic crystal demultiplexer}

We implemented an InP-membrane version of the PhC demultiplexer of Refs. [9-11]. It exploits resonant intermodal coupling at mini-stopbands (MSB) of a multimode PhC waveguide ("W5" here). The carrier converted in a higherorder mode is directionally extracted by thinning a PhC lateral cladding. Demux operation is obtained by adapting the local PhC guide width to tune the MSB central frequency in a fully selectable manner (unlike phasars). A section length of $\sim 20 \mu \mathrm{m}$ is enough for good extraction, resulting in an extremely compact device. The layout of Fig. 1 has $10 \mathrm{~nm}$-spaced channels. A tunable laser is coupled by a grating (one-dimensional here). The carriers are extracted in 4 broad channels towards integrated photodiodes, where photocurrent is measured. The through signal feeds a last integrated detector. The results are shown in Fig. 4 (middle). Channel 1 is absent due to a damaged contact pad. The crosstalk is $\sim-10 \mathrm{~dB}$ for nonadjacent channels in this first realization, with known margins for progress from alloptical tests (insets). The shape of the through signal evidences (Fig. 4 right) the selectable device action.
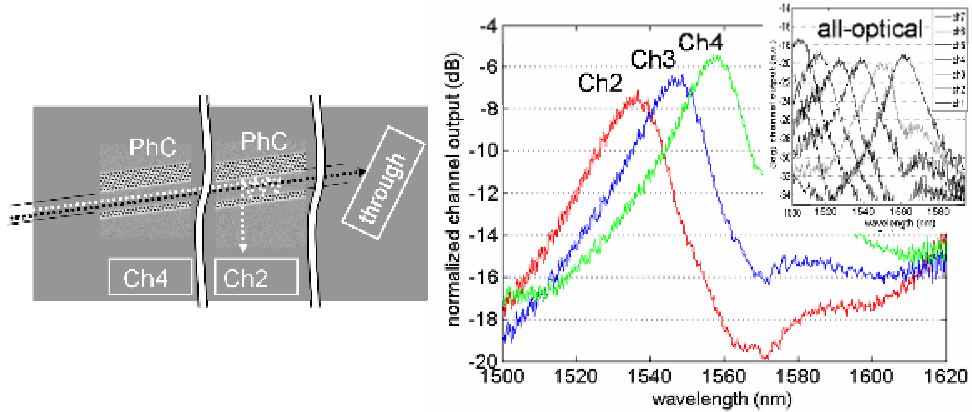

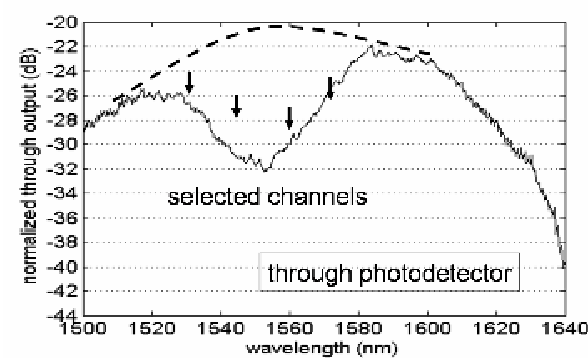

Fig. 4. (Left) Photonic crystal demux with integrated photodetectors. (Middle) Photocurrent of the channels, normalized to the grating coupler spectrum; inset: similar 7-channel all-optical measurement. (Right) Measurement of the through waveguide. The dashed line is a guide to the eye.

\section{Conclusions}

We have demonstrated a very compact multifunctional photonic crystal demultiplexer for coarse WDM in bonded InP-membrane, integrated with InGaAs p-i-n photodetectors. The interface with the outside world (fiber) is provided by efficient and compact grating couplers. Polarization diversity and crosstalk improvements of this realization show that a compact photonic crystal real-world integrated telecom device is a genuine technological option.

\section{Acknowledgements}

This work was supported by the European Union through the FP6-IST-004582 FUNFOX project. The Fraunhofer Institüt für Nachrichtentechnik, Heinrich-Hertz Institüt, Berlin is acknowledged for providing the epiwafers.

\section{References}

[1] R. Soref, "The past, present, and future of silicon photonics," IEEE J. Sel. Top. Quantum Electron. 12, 1678-1687 (2006).

[2] J. Van Campenhout et al., "Electrically pumped InP-based microdisk lasers integrated with a nanophotonic silicon-on-insulator waveguide circuit," Opt. Express 15, 6744-6749 (2007).

[3] A. W. Fang, H. Park, O. Cohen, R. Jones, M. J. Paniccia, and J. E. Bowers, "Electrically pumped hybrid AlGaInAs-silicon evanescent laser," Opt. Express 14, 9203-9210 (2006).

[4] G. Masini, G. Capellini, J. Witzens, C. Gunn, "A four-channel, 10 Gbps monolithic optical receiver in $130 \mathrm{~nm}$ CMOS with integrated Ge waveguide photodetectors," OFC 2007, PDP31.

[5] G. Roelkens, J. Brouckaert, D. Van Thourhout, R. Baets, R. Notzel, and M. Smit, "Adhesive bonding of InP/InGaAsP dies to processed silicon-on-insulator wafers using DVS-bis-benzocyclobutene," J. Electrochem. Soc. 153, G1015-G1019 (2006).

[6] D. Taillaert, F. Van Laere, M. Ayre, W. Bogaerts, D. Van Thourhout, P. Bienstman, R. Baets, "Grating couplers for coupling between optical fibers and nanophotonic waveguides," Jpn. J. Appl. Phys. 45, 6071-6077 (2006).

[7] D. Taillaert, H. Chong, P. I. Borel, L. H. Frandsen, R. M. De La Rue, and R. Baets, "A compact two-dimensional grating coupler used as a polarization splitter," IEEE Photon. Technol. Lett. 15, 1249-1251 (2003).

[8] F. Van Laere, G. Roelkens, M. Ayre, J. Schrauwen, D. Taillaert, D. Van Thourhout, T. F. Krauss, R. Baets, "Compact and highly efficient grating couplers between optical fiber and nanophotonic waveguides," J. Lightwave Technol. 25, 151-156 (2007).

[9] E. Viasnoff-Schwoob et al., "Compact wavelength monitoring by lateral outcoupling in wedged photonic crystal multimode waveguides," Appl. Phys. Lett. 86, 101107 (2005).

[10] L. Martinelli, H. Benisty, O. Khayam, G. H. Duan, H. Heidrich, and K. Janiak, "Analysis and optimization of compact demultiplexer monitor based on photonic crystal waveguide" IEEE J. Lightwave Technol. 25,. 2385-2394 (2007).

[11] L. Martinelli, H. Benisty, O. Drisse, E. Derouin, F. Pommereau, O. Legouézigou, and G. H. Duan, "Impact of lithographic grid irregularity assessed on photonic crystal device selectivity," IEEE Photon. Technol. Lett. 19, 282-284 (2007). 